\title{
THE STABILITY OF A FUNCTIONAL EQUATION OF MULTIPLICATIVE DERIVATION TYPE
}

\author{
YONG-SOO JUnG* AND KYOO-HONG PARK
}

Abstract. In this paper, we investigate the stability in the sense of Ger of the following functional equation of multiplicative derivation type which was introduced by Gy. Maksa and Zs. Páles [5]:

$$
\delta(x y)=M(x) \delta(y)+M(y) \delta(x)
$$

for all $x, y \in(0, \infty)$, where $M:(0, \infty) \rightarrow(0, \infty)$ is a function satisfying $M(x y)=M(x) M(y)$ for all $x, y \in(0, \infty)$.

Mathematics subject classification (2000): 39B52, 39B72, 39B82.

Key words and phrases: multiplicative derivation, stability in the sense of Ger.

\section{REFERENCES}

[1] R. GER, Superstability is not natural, Rocznik Naukowo-Dydaktyczny WSP Krakowie Prace Mat. 159 (1993), 109-123.

[2] D. H. HYERS, On the stability of the linear functional equation, Proc. Natl. Acad. Sci. 27 (1941), 222-224.

[3] Y.-S. JunG, On the stability of the functional equation $f(x+y-x y)+x f(y)+y f(x)=f(x)+f(y)$, Math. Inequal. Appl. 7 (2004), 79-85.

[4] GY. MAKSA, Problems 18, In 'Report on the 34th ISFE', Aequationes Math. 53 (1997), 194.

[5] Gy. MAKSA AND Zs. PÁles, Hyperstability of a class of linear functional equations, Acta Math. Acad. Paed. Nyhazi. 17 (2001), 107-112.

[6] J. TABOR, Stability of the Cauchy functional equation with variable bound, Publ. Math. Debrecen 51 (1997), 165-173.

[7] S. M. Ulam, A Collection of Mathematical Problems, Interscience Publ., New York, 1960. 